\title{
VARIA
}

\section{DOS PINTURAS INÉDITAS DE JOSÉ DEL CASTILLO PARA LA DECORACIÓN DEL PALACIO DE LOS SECRETARIOS DE ESTADO EN LAS COLECCIONES DEL INSTITUTO VALENCIA DE DON JUAN}

\author{
RAÚl MARTÍNEZ ARranZ ${ }^{1}$ \\ Investigador independiente
}

\begin{abstract}
El artículo presenta dos pinturas inéditas de José del Castillo, bocetos de presentación para la decoración del Palacio de los Secretarios de Estado, residencia oficial del conde de Floridablanca en Madrid, que forman parte de un conjunto de obras en diferentes colecciones con temas de la guerra anglo-española de 1779-1783.

Palabras clave: Pintura española del siglo XVIII; José del Castillo; Gregorio Ferro.

\section{TWO UNPLUBISHED PAINTINGS BY JOSÉ DEL CASTILLO FOR THE DECORATION OF THE PALACIO DE LOS SECRETARIOS DE ESTADO IN THE COLLECTION OF THE INSTITUTO VALENCIA DE DON JUAN}

\begin{abstract}
This article introduces two unpublished paintings by José del Castillo, presentation sketches for the decoration of the Palacio de los Secretarios de Estado, the official residence of the Count of Floridablanca in Madrid. They form part of a series of works based on themes concerning the Anglo-Spanish war of 1779-1783, now in different collections.
\end{abstract}

Key words: Spanish painting; 18th Century; José del Castillo; Gregorio Ferro.

Como citar este artículo/Citation: Martínez Arranz, Raúl (2017): "Dos pinturas inéditas de José del Castillo para la decoración del Palacio de los Secretarios de Estado en las colecciones del Instituto Valencia de Don Juan". En: Archivo Español de Arte, vol. 90, núm. 357, Madrid, pp. 83-90; doi: 10.3989/aearte.2017.06.

Entre las colecciones de artes decorativas del Instituto Valencia de Don Juan, suele pasar desapercibida la pequeña, pero interesante colección de pinturas. Publicada por primera vez en 1923 por Sánchez Cantón ${ }^{2}$, la colección, compuesta por cerca de 150 obras abarca desde pintura medieval hasta obras del siglo XIX, de autores como El Greco - con su Alegoría de la orden de los Camaldulenses, ca. 1600, quizás la obra más conocida de la colección-, Bartolomé González, Claudio Coello, Raimundo de Madrazo o Eugène Boudin, entre otros.

No incluidas dentro de la publicación de Cantón, se encuentran 2 pinturas, bocetos de presentación para la decoración de una bóveda, de las que se desconoce su procedencia y cómo llegaron al Instituto. En cada una de ellas una inscripción nos indica los temas tratados: El sitio de Gibraltar (N. ${ }^{\circ}$ inventario: 6359. Óleo sobre lienzo: $39 \times 110 \mathrm{~cm}$ ) (fig. 1) y La vista de nuestra

\footnotetext{
1 museoes@yahoo.es / ORCID iD: http://orcid.org/0000-0003-3956-3516

2 Sánchez, 1923.
} 


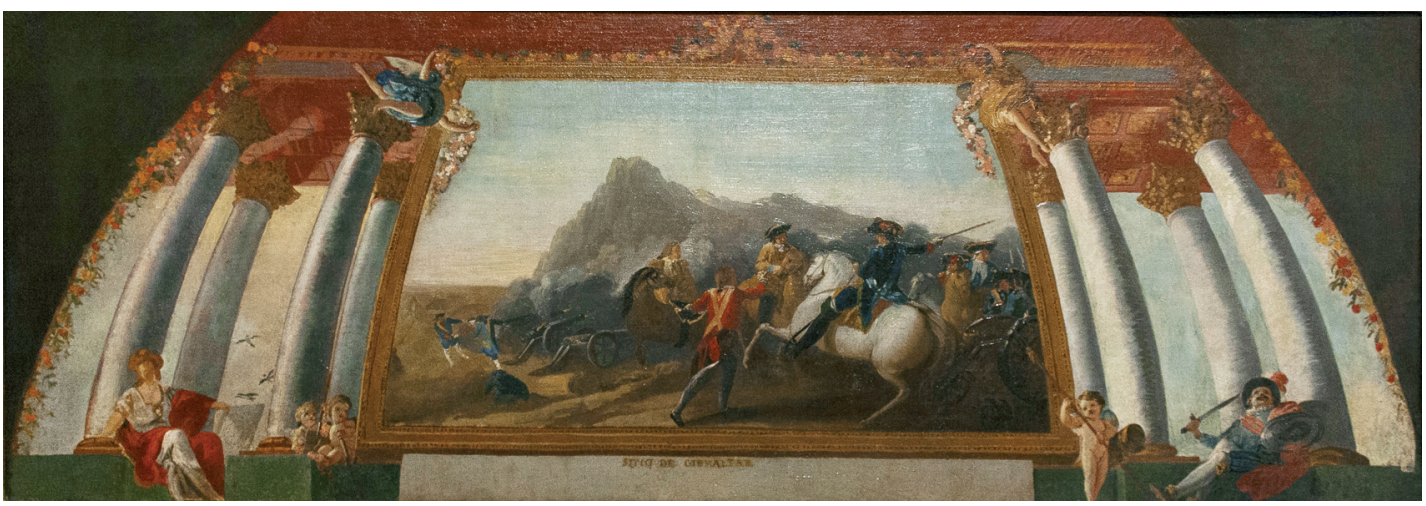

Fig. 1. José del Castillo, El sitio de Gibraltar, ca. 1787, Madrid, Instituto Valencia de Don Juan. Fotografía: Héctor Gómez.

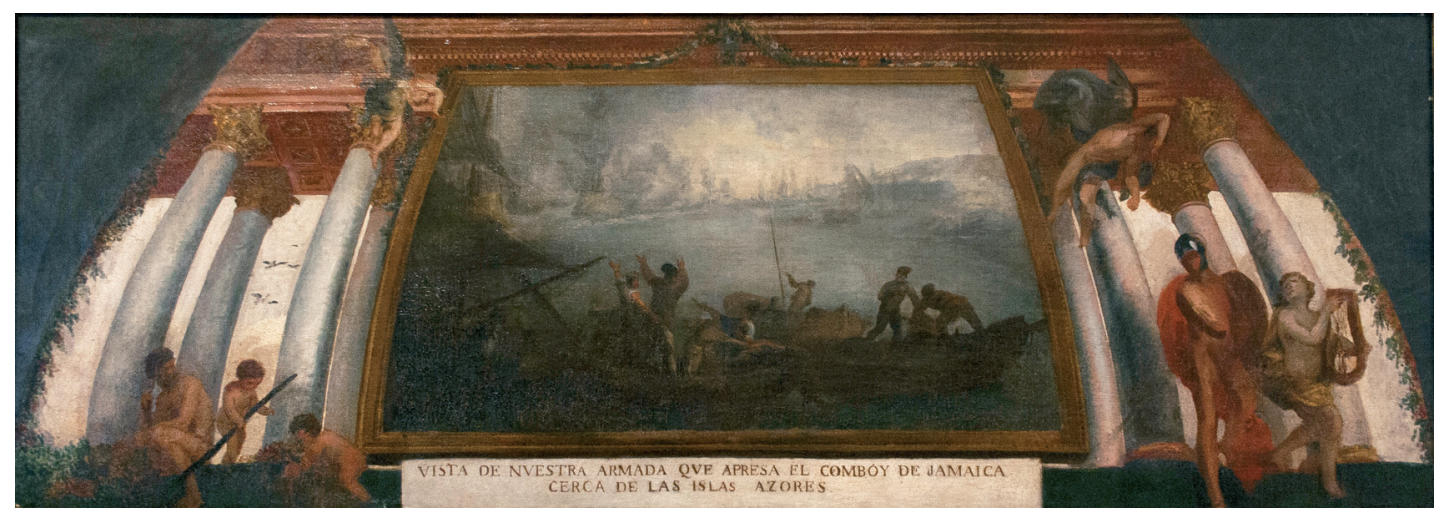

Fig. 2. José del Castillo, La vista de nuestra Armada que apresa el comboy de Jamaica cerca de las islas Azores, ca. 1787, Madrid, Instituto Valencia de Don Juan. Fotografía: Héctor Gómez.

Armada que apresa el comboy de Jamaica cerca de las islas Azores (N. ${ }^{\circ}$ inventario: 5992. Óleo sobre lienzo: $38,5 \times 110 \mathrm{~cm}$ ) (fig. 2).

Ambas pinturas están inscritas en un trapecio y se organizan con un marco fingido que acoge la escena central y que se encuentra situado ante una columnata doble de capiteles corintios en perspectiva di sotto in sú, lo que permite apreciar el techo de casetones y un fondo de celaje. Flanqueando la escena central aparecen varias figuras alegóricas en la base de la columnata y figuras aladas en la parte superior.

En la primera de las pinturas se trata el suceso de la presa del convoy de Jamaica, un hecho significativo, aunque poco conocido, que tuvo lugar durante la guerra anglo-española de 17791783. José Moñino, conde de Floridablanca y Secretario de Estado de Carlos III en aquellos años, nos narra en sus memorias ${ }^{3}$ cómo estando despachando asuntos urgentes en la secretaría de Marina, por enfermedad del entonces ministro de Marina, Pedro González de Castejón, le llegaron avisos de que Inglaterra estaba a punto de mandar dos convoyes, uno para Jamaica y otro para las Indias Orientales, con tropas, vestuarios, armas y municiones. Floridablanca ordenó que se interceptaran a su paso por las Azores, hasta donde iban a navegar juntos y escoltados por un navío y dos fragatas, para después separarse. Bajo el mando del Teniente General Luis de Córdova, una escuadra se alejó de las costas peninsulares al encuentro del convoy, interceptándolo

\footnotetext{
3 Moñino, 1829: 24-26.
} 


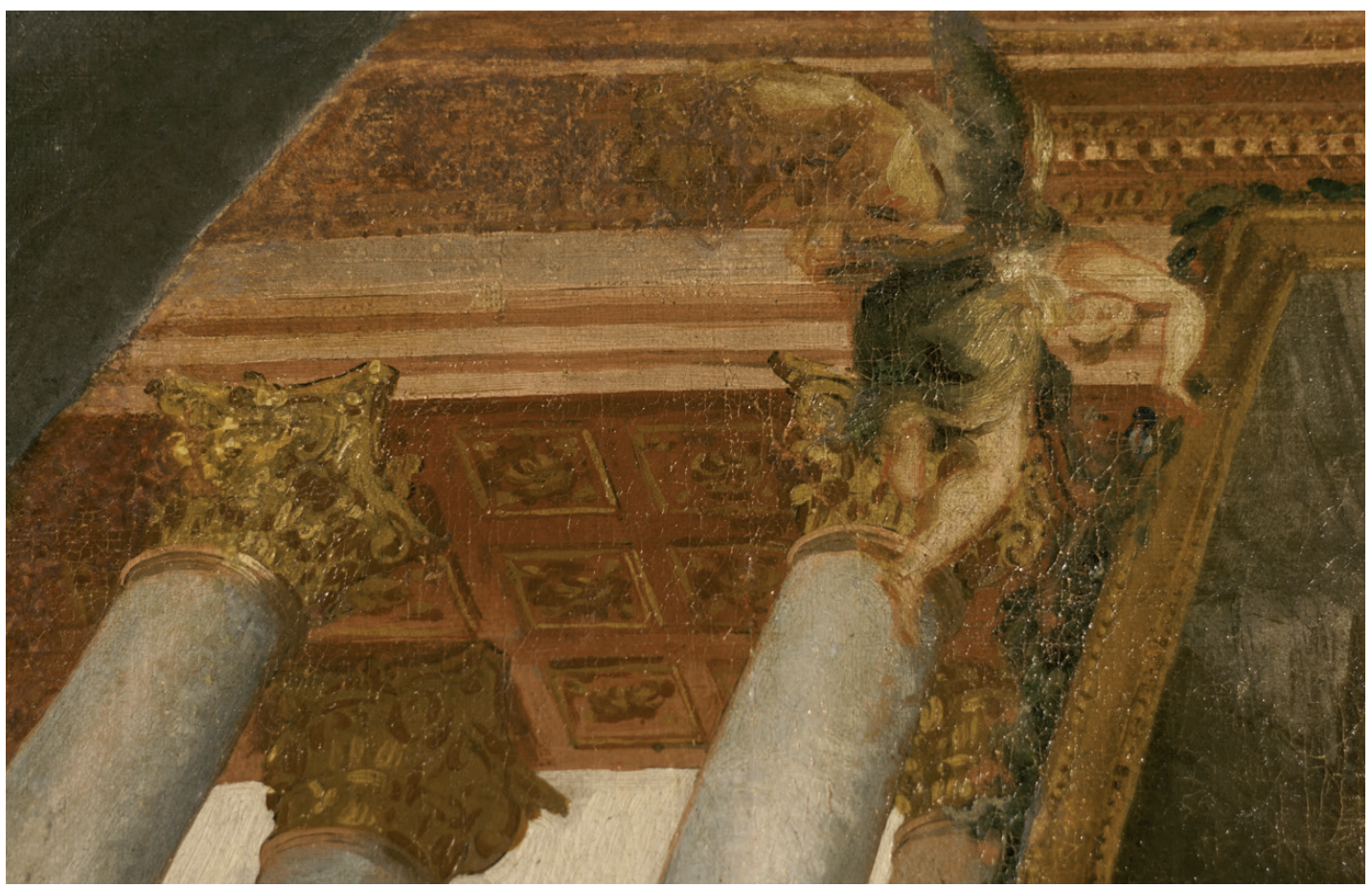

Fig. 3. Detalle de La vista de nuestra Armada que apresa el comboy de Jamaica cerca de las islas Azores. Fotografía: Héctor Gómez.

finalmente el 9 de agosto de 1780, apresando a todos los barcos, menos los 3 de guerra, que escaparon, haciendo un total de 52 buques, en lo que supuso uno de los mayores desastres logísticos de la historia naval de Inglaterra, con más de 3000 prisioneros, 1.000 .000 de libras esterlinas en lingotes y monedas y todo tipo de pertrechos militares, como 80.000 mosquetes, 3000 barriles de pólvora y vestuario y equipación para 12 regimientos de infantería, que hubieran servido para combatir a los rebeldes en Norteamérica y apoyar la guerra colonial en India ${ }^{4}$.

La escena central está ocupada por un primer plano con barcas donde varios marineros se afanan en tareas de rescate mientras que otros muestran su asombro ante el espectáculo de una gran escuadra naval cubierta de humo en el horizonte, de una manera que sugiere un combate más importante de lo que realmente fue, dado que no se llegó a perder ningún barco. Fuera de la escena central aparecen dos grupos de figuras en la base de la columnata. A la izquierda, Hércules sentado junto con un amorcillo que porta la clava observan lo que hace otro amorcillo, más abocetado, que parece recoger algo del suelo. La presencia de Hércules en este tipo de ciclos alegóricos es habitual ${ }^{5}$, sobre todo por su "patronazgo" sobre la monarquía española desde tiempos de Carlos I, además, en este caso, habría que añadir la referencia geográfica al estrecho de

4 Gaceta de Madrid, n. ${ }^{\circ}$ 69, 29 de agosto de 1780: 633-640.

${ }_{5}^{5}$ En el ámbito cortesano, la figura de Hércules aparece, por ejemplo, en el ciclo de lienzos que Francisco de Zurbarán pintó en 1634 para el Salón de Reinos del Palacio del Buen Retiro y en el gran fresco con la Alegoría del Toisón del Oro, de Luca Giordano (1697) del Casón del Buen Retiro, restauradas hacia 1778 por José del Castillo y Andrés de la Calleja y que se completaba con 16 escenas con los trabajos de Hércules localizadas en los entrepaños de las ventanas, escenas perdidas pero conocidas a través de estampas obtenidas a partir de bocetos realizados por el propio José del Castillo. Además de en estas obras, Hércules aparece en varios frescos del Palacio Real, como en el de la Apoteosis de la monarquía española de Tiépolo (1764), la Apoteosis de Hércules, de Bayeu (1760-70) y la de Mengs (1762-1764), entre otros. 


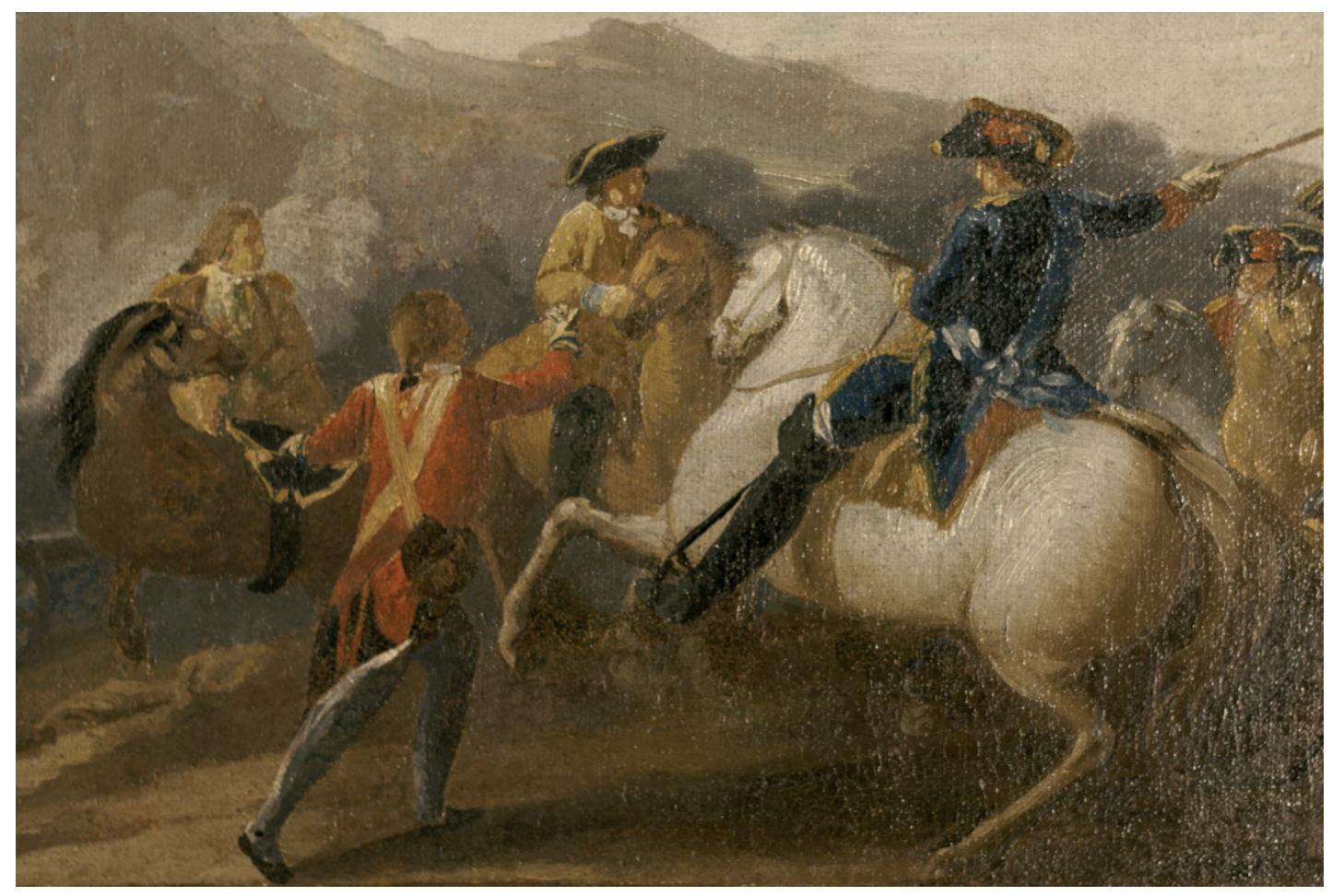

Fig. 4. Detalle de la escena central de El sitio de Gibraltar. Fotografía: Héctor Gómez.

Gibraltar -las columnas de Hércules de la antigüedad- lugar de conflicto por excelencia en diferentes guerras anglo-españolas 6 . A la derecha de Hércules, dos figuras, una con una lira, y otra, inacabada, tocada con un casco metálico, pudieran representar a Apolo y Mercurio como representación de las artes y el comercio respectivamente, otra vez figuras alegóricas habituales en este tipo de ciclos. Menos clara es la presencia de las dos figuras aladas de la parte superior, sin atributos, y cuyas actitudes parecen responder a lo que sucedería en el cerramiento de la bóveda, cuyo boceto está todavía sin localizar (fig. 3).

El asunto de la otra pintura conservada es el sitio de Gibraltar de 1779, o Gran Sitio, el más largo y duro de los realizados durante el siglo XVIII. Este sangriento episodio terminó el 3 de septiembre de 1783, con la firma de la paz de Versalles, que supuso, si no la cesión de Gibraltar, sí la de la isla de Menorca que había sido recuperada poco antes, además de las dos Floridas y zonas de Honduras y Campeche.

La escena central acoge una escena bélica en la que una figura a pie con casaca roja y un tricornio en una mano, se dirige a otra a caballo -con ecos evidentes del Caballo blanco en corveta de Velázquez (1634) del palacio real que parece ordenar con su bastón de mando que comience la batalla (fig. 4). A su alrededor se disponen varias figuras a caballo y a pie, y en un segundo plano, una batería de cañones disparando con gran humareda, al fondo se reconoce el característico perfil del peñón de Gibraltar. Acompañando la escena aparecen dos figuras aladas con guirnaldas de flores en la parte superior; en la inferior, a la izquierda, una representación de la arquitectura militar, siguiendo la iconología de Cesare Ripa ${ }^{7}$, representada como una figura

${ }^{6}$ Desde la conquista angloholandesa de Gibraltar en 1704 durante la Guerra de Sucesión Española, la plaza ha sido objeto de varios intentos de recuperación por parte de España en el siglo XVIII, en 1704-05, 1727 y 1779-1783.

7 Ripa, 1645: 40. 
femenina lujosamente vestida que muestra un plano de una fortificación hexagonal y lleva una cadena de oro con un gran diamante en el cuello. Acompañan a la figura dos amorcillos, uno de ellos sosteniendo una pala y el otro una herramienta no identificada. La representación alegórica se completa con las golondrinas volando en el fondo, otro emblema de la construcción asociado a la arquitectura militar, alusión a la manera en que estas aves construyen sus nidos con barro.

Como pendant de la arquitectura aparece a la derecha una representación del arte militar, en la figura de un soldado a la usanza del siglo XVII, blandiendo una espada y sujetando un escudo. Un amorcillo le acompaña portando una lanza mientras se apoya en el extremo de un ariete, de manera similar a como aparece en el luneto de los genios de la guerra de la bóveda de la Sala de Besamanos de María Luisa de Parma en el Palacio Real de Madrid, pintada por Antonio González Velázquez en 1763 con el tema de Apolo y Minerva premiando los talentos.

Estas dos pinturas formarían parte de un conjunto de obras que han aparecido recientemente en el mercado del arte, todos ellos de formatos horizontales, con una escena central que enmarca un asunto militar y en algunos casos con personajes en común. Pinturas que, según Jesús López Ortega ${ }^{8}$ habría que poner, creemos que con razón, en relación a la decoración del Palacio de los Secretarios de Estado, primera residencia oficial del conde de Floridablanca. Este palacio fue comenzado a construir en 1775 por Francisco de Sabatini para Pablo Grimaldi y Pallavicini, Marqués de Grimaldi, en unos terrenos próximos al Palacio Real, junto al convento de Doña María de Aragón. Como ha estudiado Selina Blasco, en aquellos años, la zona se encontraba inmersa en una serie de cambios urbanísticos destinados a embellecer los alrededores de la residencia regia, en cuyo proyecto se incluyó la construcción de un palacio para el Secretario de Estado, que serviría no sólo de residencia oficial sino que también albergaría oficinas administrativas, hasta ese momento localizadas en el Palacio Real. No obstante, Grimaldi no llegó a habitar el palacio, dado que dimitió a finales de 1776, siendo su sucesor el siguiente Ministro de Estado, el conde de Floridablanca, el primero en habitar el palacio en 1782. No se conocen planos del palacio en ese momento y lo que se conserva en la actualidad, tras las demoliciones parciales de 1930-31, es fruto de las reformas efectuadas a principios del siglo XIX para Manuel Godoy, primer ministro de Carlos IV, que convirtió el palacio en su residencia particular.

En su doble función de residencia oficial y particular de la Secretaría de Estado, tuvo una decoración acorde con su estatus, con pinturas, muebles y objetos decorativos procedentes en su mayor parte de las colecciones reales y de la Real Academia de Bellas Artes ${ }^{9}$. Cabe destacar que entre las obras que colgaban en el palacio se encontraban piezas procedentes de dos presas realizadas durante el transcurso de la guerra anglo-española, la de la fragata toscana Tetis y la de la inglesa Westmorland, entre las que se incluían obras como los retratos de George Legge, vizconde de Lewisham (1778) y Francis Basset, I barón de Dunstanville (1778) de Pompeo Batoni, actualmente en el Museo del Prado ${ }^{10}$.

La decoración de los techos del palacio se realizó entre 1787 y 1791 por los pintores José del Castillo (1737-1793) y Gregorio Ferro (1742-1812), discípulos de Corrado Giaquinto, según conocemos por diversa documentación que se conserva en el archivo del Palacio Real de Madrid. En aquellos años, José del Castillo, pintor de cartones en la fábrica de Santa Bárbara, se encontraba en una situación económica bastante precaria y "en este apuro acudió a la bondad del rey, por medio del Conde de Floridablanca, quien echo cargo de sus servicios, y situación, con aprobación de S.M. le dio la comisión de pintar los techos de la Casa del Rey que habitaba, señalandosele mensualmente en Correos quince mil reales con el fin de que se exercitase en el manejo del fresco, para con el ser empleado en otras de S. M." Respecto a la colaboración de Gregorio Ferro se conoce que "[...] por Real Orden de su magestad el señor Don Carlos III, comunicada por el Exmo. Señor Conde de Floridablanca en 20 de julio de 1787, se empleo cinco años pintando a Fresco, en compañia del teniente director, Don Josef Castillo, los techos y bobedas de las Casa del Rei que habitaba, en Madrid, el Ministro de Estado, con la asignación de diez y ocho

\footnotetext{
8 López, 2014: 105-106.

9 Blasco, 2005: 45-46.

${ }^{10}$ Luzón, 2002: 207-209.
} 


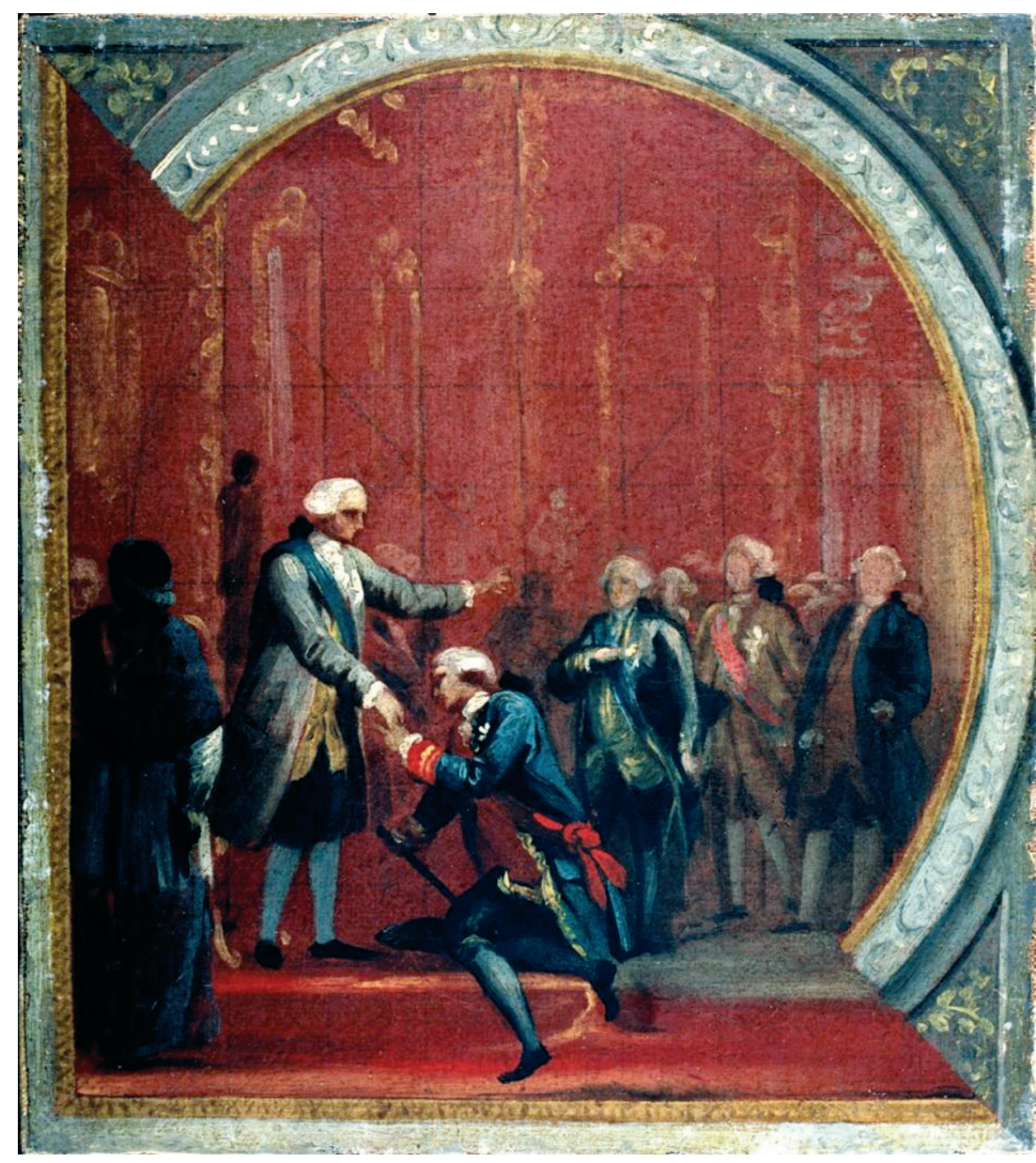

Fig. 5. José del Castillo, Boceto para una escena histórica, ca. 1787. Madrid, Museo Lázaro Galdiano (C) Fundación Lázaro Galdiano. Madrid.

mil reales anuales"11. De los frescos conservados in situ en el palacio, actual Centro de Estudios Políticos y Constitucionales, y los que se trasladaron al Ministerio de Marina del Paseo del Prado hacia 1930, es difícil discernir cuáles son obra de Gregorio Ferro o de José del Castillo, aunque se atribuyen al último los techos de las salas conocidas como del Rapto de Ganímedes, Apolo y las Musas y los signos del Zodiaco. El resto de los techos se consideran ya de la época en que Godoy habitó el palacio ${ }^{12}$.

En base a esta información y por razones estilísticas, habría que atribuir a José del Castillo la realización de estos dos bocetos inéditos, junto al de Don Pedro de Cevallos desembarca en el puerto de Buenos Aires de la Galería Caylus de Madrid y, probablemente, de los bocetos -los otros dos están firmados por Ferro en 1788-, subastados en la casa Sotheby's de Montecarlo en 1985 y en Nueva York en 2008, Embarco en el puerto de Brest y Combate en el canal de Inglaterra ya citados por López Ortega ${ }^{13}$ y con los que comparte el formato de quadro riportato. A estas cinco obras habría que añadir otra más pequeña $(24 \times 21 \mathrm{~cm})$, indudablemente relacionada con este conjunto, y de título Boceto para una escena histórica, que se conserva en el Museo Lázaro Galdiano de Madrid (n. ${ }^{\circ}$ de inventario 03893) (fig. 5) y cuyo carácter de proyecto decorativo se ve acentuado además por mostrar dos soluciones para su encuadre, una en formato

\footnotetext{
11 Blasco, 2005: 47-48.

12 Blasco, 2005: 49.

13 López, 2014: 106-107.
} 
ovalado y otra rectangular separadas por una diagonal ${ }^{14}$. Hasta ahora considerado como anónimo del siglo XVIII, representa en un ambiente palaciego a Carlos III subido a un estrado acompañado de un personaje ataviado con una casaca azul, bastón y banda roja, que, rodilla en tierra, se dispone a besarle la mano ante la mirada de un grupo de cortesanos. Este personaje aparece vestido con el mismo uniforme que en el cuadro de la galería Caylus, pudiendo identificarse con Pedro de Cevallos, y la escena bien pudiera ser su nombramiento en 1776 como virrey del Río de la Plata, un nuevo Virreinato creado expresamente para Cevallos mientras durara su expedición militar a las provincias de la América meridional, pero que acabó teniendo carácter permanente desde 1777 hasta la independencia en 1814.

Aunque el boceto del Comboy de Jamaica se encuentra inacabado y con algunas pérdidas de capa pictórica, la técnica de ambos es comparable a la de los otros bocetos atribuidos a Castillo. En todos ellos encontramos un tratamiento similar de la pincelada, fluida y pastosa así como un modo particular de marcar las zonas iluminadas mediante pinceladas menudas, que se pueden observar, por ejemplo, en los capiteles y casetones de la arquitectura de ambas pinturas, en las figuras de la escena central del Sitio de Gibraltar, en el casco de Mercurio o en el manto de Apolo del Comboy de Jamaica, una característica que encontramos en otros bocetos conservados de mano de Castillo, como las cuatro alegorías del Museo del Prado (P07726, P07727, P07728 y P07729) o Los santos niños Justo y Pastor conducidos al martirio, obra de 1790, de las colecciones del Museo Lázaro Galdiano ( . $^{\circ}$ de inventario 03582), con el que comparte además un aire más académico. Similares también son los amorcillos presentes en varias de sus obras conocidas, como en las ya citadas alegorías del Museo del Prado y en donde se percibe la influencia de su maestro Corrado Giaquinto. Otras semejanzas aparecen en dibujos y academias, como en la figura de la arquitectura militar que recuerda a la conocida sibila Eritrea de Miguel Ángel, que Castillo pudo admirar en la Capilla Sixtina durante sus estancias en Roma y que aparece dibujada en el Cuaderno italiano III, de $1762^{15}$. Similar postura tienen también el Mercurio del Comboy de Jamaica y uno de sus dibujos de 1759, la Academia de desnudo masculino con diadema ${ }^{16}$.

Este conjunto de obras atribuidas a José del Castillo presenta un aspecto inédito dentro de la producción del artista, conocido sobre todo por su labor como cartonista, estudiada por expertos como José Luis Morales o Jesús López Ortega, que no hace sino confirmar el gran interés de su obra, injustamente olvidada. La aparición de este grupo de pinturas, tanto las de Castillo como las de Ferro ${ }^{17}$ nos habla de la importancia que tuvo el Palacio de los Secretarios de Estado dentro de las empresas decorativas de finales del reinado de Carlos III, y destaca sobre todo por la novedad en la elección de temas de historia contemporánea, con una clara intención propagandística, alejada de los ciclos alegóricos o mitológicos habituales en las decoraciones palaciegas del momento y que sólo encontrará eco en una serie de tres lienzos sobre la recuperación de la isla de Menorca por el duque de Crillon (1781/1782) pintados por Mariano Salvador Maella entre 1788 y 1791 para decorar la escalera de honor de la Casita del Príncipe de El Escorial, lugar donde todavía se encuentran ${ }^{18}$.

\footnotetext{
14 Pérez, 2005: 198.

15 López, 2014: 220. D. 213 (Fig. 483) Museo Nacional del Prado D5542/64 y /65.

${ }^{16}$ López, 2014: 148. D.19 (Fig. 289) Biblioteca de la Facultad de Bellas Artes de la Universidad Complutense, Madrid.

${ }^{17}$ Los lienzos de Gregorio Ferro relacionados con este ciclo decorativo son: Entrega de las llaves a Cevallos por el Gobernador de Sacramento, firmado y fechado en 1787, de la Galería Caylus; Salen huiendo despavoridas las gentes del puerto de Plimouth a vista de las armadas de Francia y España y Se unen los navios del Rey con la armada francesa a la vista de la Coruña, firmados y fechados en 1788 y subastados en Sotheby's; Carlos III dando las órdenes para la declaración de guerra con Inglaterra, firmado y fechado en 1788, del Museo de Pontevedra y El Teniente General Cevallos se despide de Carlos III, de propiedad particular.

18 Luna, 2002: 386-389.
} 


\section{BIBLIOGRAFÍA}

Blasco Castiñeyra, Selina (2005): El Palacio de Godoy. Madrid: Centro de Estudios Políticos y Constitucionales.

López Ortega, Jesús (2014): El pintor madrileño José del Castillo (1737-1793), tesis doctoral inédita, 3 vols. Madrid: Universidad Complutense de Madrid.

Luna, Juan José (2002): "Mariano Salvador Maella (1739-1819). Desembarco de las tropas españolas en Mahón en Cala Mesquida”. En: 1802: España entre dos siglos y la devolución de Menorca (2002). Madrid: Sociedad Estatal de Conmemoraciones Culturales.

Luzón Nogué, Jose María (2002): El Westmorland: recuerdos del Gran Tour. Sevilla: Fundación El Monte.

Moñino y Redondo, José (1829): Escrito clásico del reinado del Sr. D. Cárlos III, que se cita al fólio 465 del tomo noveno de la nueva edicion de la historia general de España del P. Mariana. Madrid: Imprenta de los hijos de Doña Catalina Piñuela.

Pérez Sánchez, Alfonso Emilio (2005): Pintura española de los siglos XVII y XVIII en la Fundación Lázaro Galdiano. Madrid: Fundación Lázaro Galdiano.

Ripa Perugino, Cesare (1645): Iconología di Sesare Ripa Perugino. Venecia: Cristoforo Tomasini.

Sánchez Cantón, Francisco Javier (1923): Catálogo de las pinturas del Instituto de Valencia de Don Juan. Madrid: Instituto Valencia de Don Juan.

Fecha de recepción: 08-IV-2015

Fecha de aceptación: 03-XI-2015 